\title{
物联网技术在建筑智能化系统中的应用
}

\author{
姚为喜* \\ 万达信息股份有限公司 上海 200041
}

\begin{abstract}
摘 要: 在建筑行业中, 物联网技术是实现智能化建筑系统的媒介。随着现代科学技术的进步和物联网的快速发 展, 智能建筑离我们越来越近。物联网时代建筑智能系统技术应用模式的出现, 实现了信息化、全球化、多功能的目 标。只有适应物联网时代信息技术的飞速发展, 才能在当今时代实现稳定、可持续的发展。为了让社会生活更加智能 化, 物联网给人们带来了很多便利, 比如刷卡机、刷脸支付设备等, 这些都应用了物联网技术。在建筑领域, 物联网 下的智能系统帮助建筑行业实现施工控制、安全预防, 或更多的智能化施工模块。通过建筑智能化系统，建筑行业在 实现建筑施工的过程中，可以保证更好的对施工过程进行智能化控制，保证在施工领域更加安全的工作，也可以更好 的提高工作效率和工作质量，促进建筑行业的发展。
\end{abstract}

关键词: 物联网技术; 建筑智能化; 应用

DOI: https://doi.org/10.37155/2717-557X-0207-4

\section{1 物联网}

物联网是新一代的信息技术中非常重要的组成部分, 其是在互联网的基础之上, 运用电子信息技术, 以及无线通 信技术等多项技术有机地结合到一起, 形成的一种覆盖诸多事物的网络, 与其说物联网是物品与物品之间相连接的互 联网, 还不如说物联网是将互联网进一步扩展而来, 也是将业务与应用有机地结合到一起。要想促进物联网的发展, 就需要工作人员不断对其应用进行优化与创新, 这才是推动物联网发展的关键。物联网是在互联网的基础之上, 合理 使用无线通信技术、全球定位系统等多项信息传感设备, 以相关协议为基准, 将物品与互联网有机地结合到一起, 从 而实现信息传递、远程监控、安全防范等功能, 所以物联网有着极为广阔的发展空间 ${ }^{[1]}$ 。近几年, 随着科学技术的不 断发展, 物联网也逐渐向智能化的方向发展。物联网技术与建筑有机地结合到一起, 工作人员可以通过物联网的方 式, 对智能建筑中设备的运行状态、空间的运用情况等有效地管理与监督, 并且在管理过程中, 一旦发现问题, 能及 时对其进行处理, 以保证建筑能够正常运行。如若将智能建筑的各项信息数据, 全部记录到建筑数字化模型之中, 工 作人员可以通过物联网的方式，随时随地查看各项数据信息的变化情况。

\section{2 智能建筑}

随着人们生活质量越来越好, 人们对建筑的需求也随之不断增多, 而科技的进步也促进建筑实现智能化, 从传统 混凝土结构建筑逐渐向智能化方向转变, 智能化建筑是在传统建筑的基础之上演变而来, 为人们提供更加舒适、安 全、智能的生活环境。智能建筑是将多个学科、信息技术、通信传输等个各类技术, 综合到一起的一项现代科学技术 产物。虽然我国很多地区都建设了智能化建筑, 但是我国在建筑智能化发展时间较短, 所以智能建筑中还是存在不少 问题, 其就包含了施工企业的施工理念陈旧, 相关的技术水平不足, 设计理念不够新颖, 建筑中的智能化系统并没有 达到预期的效果。这不仅消耗了大量的人力资源, 还浪费了大量的物力, 虽然很多地区建设了智能化建筑, 但是无法 真正做到正常运转。而且智能建筑所涉及的技术众多, 随着时代的进步, 科学技术的不断发展, 人们对智能建筑的需 求不再局限于居住安全, 而是集实用、可靠、高效等多项功能于一身的建筑 ${ }^{[2]}$ 。我国针对这一情况, 在《智能建筑设 计》标准中, 对智能建筑又有了全新的定义, 并在其中重点强调了对信息数据的收集、传递、应用、管理, 同时也提 出了更加人性化的概念, 包含了环保、节能等, 以此来推动智能建筑的发展, 为人们提供安全、舒适、节能环保等各 项功能于一身的建筑。

*通讯作者：姚为喜，1979.9，男，汉族，安徽淮南，本科，高级工程师。研究方向：建筑智能化项目的技术与管理。 


\section{3 物联网技术在建筑智能化系统中的应用发展策略}

\section{1 实现全方面监控}

对物联网技术下的建筑智能化系统应采取全方面的监控措施, 并留有一套应急措施。这要求监控物联网技术系统 的是一个有责任心的人, 实时监控系统, 保证系统可以正常运行, 随时可以进行信息服务的整合, 能够对服务操作进 行收集统一, 可以在各个层面对信息进行处理和总结, 通过有效的监控措施, 可以在任何时间提醒管理员, 在问题还 没有变严重之前提醒管理员，降低损失。

3.2 提升自动化管理效率

信息时代中自动化处理已经很普遍了，随着物联网技术的不断发展，使得对它的运行管理要求也越来越高，仅靠 人工运行, 根本无法解决企业的发展需求, 因此自动化管理就开始不断发展。物联网技术平台的运行与维护, 一定要 达到最高程度的自动化管理，这也是信息时代发展的必然结果 ${ }^{[3]}$ 。

\section{3 优化标准化管理}

对建筑智能化施工系统进行一定的严格管理, 需要结合物联网技术的规范化, 进行操作。同时, 要更好地实施系 统中的监管控制，确保建筑智能化系统足够的安全，使建筑行业及施工单位能更好地接受物联网技术服务。

3.4 加强一体化模式管理

利用数据的更新周期，进行前期的应用构架设计和评估，物联网技术运行管理的同时，要注重平台维护、故障处 理以及安全管理。若要达到虚拟资源的统一管理的目标, 就必须实现有效利用自动化操作, 实现计算机数据中心高效 便捷的集成管理。

3.5 技术和流程需要持续运行及维护

首先实施业务指导, 进行有效的物联网技术运营管理, 通过现代化和自动化的运营工具实时监控和警报, 减少事 件发生，提高反应能力。只有改进自身管理和运行的不足，才能提高运行和维护的服务能力 ${ }^{[4]}$ 。

3.6 注重设备的定期检查

为了保证系统运行的高质量, 需要定期检查设备的工作状态以及性能的稳定性。除此之外, 使用单位还需要建立 和完善相关的巡检流程和制度, 来检查涉及的全部硬件的运行情况来保证系统能够正常运行。需要注意的是, 要按照

“从外到内、从主到次” 的顺序原则进行检查。举例来说: 首先要检查的是, 包括机房内温度、灰尘、通风以及湿度 等在内的物理环境; 其次是要对设备的运行情况进行实时记录, 及时查看运行记录来检查设备是否处于正常的运行状 态; 最后, 着重检查机房的网络运行环境情况以及机房内各种线路的质量情况等, 这将为设备的正常运行提供有力的 保障服务。

\section{7 注重服务器的维护}

服务器系统的核心是日志管理制度。作为核心, 其为各种服务与功能提供了关键的载体。为了确保服务器能够安 全稳定的运行, 可以注重两个方面:一方面, 使用专用机柜储存服务器, 将其放在机房, 主要是进行散热、通风, 备 有备用电源、吸湿、防火、空调等; 另一方面, 对服务器的访问、内存以及磁盘空间进行监控, 并且定期对服务器内 所含的病毒进行检查与扫描, 来避免各种负面因素给服务器带来破坏, 用科学的方法对服务器进行保护。服务器的维 护, 主要依靠其日志文件系统。服务器一旦被打开, 日志文件系统则主动进行加载和运行。每次访问服务器时, 管 理员需要把和访问有关的内容录人到日志文件中, 然后存储在服务器中。当服务器出现故障时, 出现故障的时间、原 因、排除措施等会第一时间录人到日志文件中, 为开发与研究人员提供可靠的、有参考价值的资料, 从而增强系统的 性能、提高系统的稳定性 ${ }^{[]]}$。

3.8 注重数据的备份

伴随着物联网技术的快速发展，硬件、软件系统的可靠性也得到了大大的增强。但是依然很难避免内部或者外部 因素(破坏性病毒攻击、破坏、不当操作)自然灾害等的影响导致系统发生故障。所以，对数据库进行定期的备份很关 键，这样可以保证系统运行的稳定与安全。

\section{9 注重系统的维护}

建筑智能化系统是由很多子业务系统构建而成。各种不同的服务器上都有子业务系统, 并且运行着多种不同的程 序, 这使得服务器的维护与管理变得更加复杂与困难。业务运营支撑系统的产生给系统管理带来了便利, 该系统能够 
统一管理数据, 实现数据的共享, 通过构建这样一个统一的工作平台, 全部业务都可以在该平台上及时处理。该系统 的建立给系统的控制、监视和管理提供了保障, 还简化了系统操作程序，提高了检索系统故障的效率，确保了系统的 正常运行效率。

\section{4 结束语}

综上所述，近几年，随着物联网技术应用范围不断扩大，在智能建筑中也逐渐广泛起来。智能化建筑合理运用物 联网技术，不仅能够帮助员工有效控制建筑中各类系统，还能为居民提供更加舒适的服务内容，为居民提供安全、高 效、智能的居住环境。与此同时, 物联网技术在智能化建筑中应用, 不仅完善了安防系统中所存在的不足之处, 还能 减少对周边环境地污染，从而推动建筑智能化的发展。

\section{参考文献:}

[1]朱玉强.建筑智能化技术在物联网时代的发展和应用分析[J].工程技术研究,2019,4(11):40-41.

[2]张天莹.建筑智能化技术在物联网时代的发展和应用 [J].科技创新导报,2019,16(13):167+169.

[3] 钱汇源.建筑智能化技术在物联网时代的发展和应用分析[J].科技创新与应用,2019,(5):155-156.

[4]刘恒宇.应用物联网技术的建筑智能化发展综述[J].住宅与房地产,2018,(31):152+241.

[5]梁志云.建筑智能化技术在物联网时代的应用及发展探讨[J].居舍,2018,(21):222. 